\title{
Sexual maturation and fecundity of wild and domestic Norway rats (Rattus norvegicus)
}

\author{
B. R. Clark* and E. O. Price $\dagger$ \\ School of Biology, Chemistry and Ecology, State University of New York College of \\ Environmental Science and Forestry, Syracuse, New York 13210, U.S.A.
}

\begin{abstract}
Summary. A population of captive-reared wild Norway rats and two stocks of domestic rats were compared for various parameters of sexual maturation and fecundity.

Males did not differ in age at the first appearance of spermatozoa in the testes but wild males were significantly older than Long-Evans and Sprague-Dawley domestic males at first copulation with a hormone-induced oestrous female. Wild females were significantly older than domestic females at the time of vaginal opening, first oestrus and first conception. Stocks did not differ in length of the first oestrous cycle. Wild females produced significantly smaller litters than their domestic counterparts. Domestic rats were significantly heavier than wild rats at the various stages of sexual maturation. The results support the hypothesis that domestication of the rat has been accompanied by genetic and/or environmental changes that accelerate sexual development and improve breeding success under laboratory conditions.
\end{abstract}

\section{Introduction}

Sexual maturity is believed to occur earlier for domestic Norway rats (Rattus norvegicus) than for their wild progenitors (King \& Donaldson, 1929; King, 1939). However, age at sexual maturity may be related to genetic changes accompanying domestication (Price \& King, 1968) or to environmental variables (Sadleir, 1969) or both. Artificial selection (both intentional and unintentional) for early sexual maturation may maximize productivity for animal breeders and is likely to have occurred. However, animals reared in the laboratory are exposed to environmental variables (e.g. nutrition, photoperiod) that may accelerate maturation and improve fecundity.

The following study compares a population of captive-reared wild Norway rats with two stocks of domestic rats in regard to the age at which sexual maturity and reproductive success is attained.

\section{Materials and Methods}

The wild-genotype stock consisted of laboratory-reared offspring of adults trapped at six locations in the vicinity of Syracuse, New York. The 24 wild males and 26 wild females were selected from 8 litters. Domestic rats consisted of 27 Sprague-Dawley males (selected from 9 litters), 26 Sprague-Dawley females (10 litters), 23 Long-Evans males (8 litters) and 25 Long-Evans females (10 litters). No more than 7 rats from any breeding pair were used.

* Present address: Bristol Hill Farms, Bristol Rd, East Chatham, New York 12060, U.S.A.

$\dagger$ Present address: Department of Animal Science, University of California, Davis, California 95616, U.S.A. 
Large litters were culled to 10 young immediately after parturition. Litters with fewer than 6 offspring were not used. Sex was determined at 10 days of age and litters were reduced to 7 offspring, as 3 males and 4 females whenever possible. Excess young were removed without regard to general size or vigour. When weaned, subjects were housed in groups of 2-4 animals of one sex in $35.6 \times 35.6 \times 17.8-\mathrm{cm}$ wire-mesh cages. No more than 3 males or 4 females were chosen from litters with heavily biased sex ratios. A combination ear punch-toe clip numbering system was used for identification.

Rats were maintained under $22.2 \pm 2.8^{\circ} \mathrm{C}$ ambient temperature and exposed to $16 \mathrm{~h}$ light (06:00-22:00 h) $/ 24 \mathrm{~h}$. Charles River Rodent Diet and water were always available.

All animals were handled for 1-2 min daily beginning at 26 days of age until vaginal opening (females) or 32 days of age (males). Handling consisted of grasping the tail and body of the animal with gloved hand and lightly stroking the rat on the back from head to tail with the index and middle fingers of the other hand.

Attainment of sexual maturity in the male rats was measured by the first appearance of scrotal testes, mature spermatozoa and copulation with a hormone-induced oestrous female. Males were observed daily, starting at 25 days of age, to determine the age at which the testes descended into the scrotum. Starting at 32 days of age a testicular biopsy was performed on each male every 3rd day to determine the time of first appearance of mature spermatozoa in the testes and/or epididymis. The biopsy (Martin \& Richmond, 1972) consisted of inserting a $38 \mathrm{~mm}$, 16-gauge hypodermic needle into the testis of a lightly etherized rat with care taken to avoid piercing the testicular vein. During insertion, seminiferous tubules, interstitial tissue, and fluid were forced into the needle. A $50.8 \mathrm{~mm}, 25$-gauge hypodermic needle was used as a plunger to expel the contents of the 16-gauge needle into a drop of saline solution $(9 \mathrm{~g} \mathrm{NaCl} / 1)$. The sample was examined under the microscope for mature spermatozoa. Testes were sampled alternately.

Three days after mature spermatozoa were detected in the biopsy and every 3rd day thereafter males were weighed and paired overnight in clean cages with a domestic female in which oestrus was induced hormonally. Vaginal smears were taken the following morning to verify the presence or absence of spermatozoa. Pairings were made between 15:00 and 20:00 h and each female weighed less than her male partner.

Oestrus was induced in Sprague-Dawley and Long-Evans females by an intramuscular (i.m.) injection of $0.1 \mathrm{mg}$ oestradiol benzoate in $0.5 \mathrm{ml}$ sesame oil $60-72 \mathrm{~h}$ before pairing. At 6-8 h before pairing a second i.m. injection of $1.0 \mathrm{mg}$ progesterone in $0.5 \mathrm{ml}$ sesame oil was administered (Brown, 1974). Females were placed with proven males immediately before testing to verify sexual receptivity (i.e. exhibited lordosis when mounted).

Sexual maturity in the female was measured by the onset of vaginal opening, first oestrus and first successful conception. Age at vaginal opening was determined by daily inspection beginning at 25 days of age. Body weight was recorded at this time. Starting at the time of vaginal opening, vaginal smears were examined daily: age and weight upon first appearance of cornified cells in the vagina (first oestrus) were recorded.

Immediately after ascertaining first oestrus, females were paired with a Sprague-Dawley or Long-Evans male of proven fertility. Males remained with females until parturition or obvious signs of pregnancy. Shredded paper was provided for bedding and nesting material. The time of conception was estimated from the presence of spermatozoa in the vaginal smear or by subtracting 22 days from the date of parturition (Asdell, 1964). Number and sex of offspring in each litter were recorded.

Necropsies were performed on 4 wild females that had not conceived after reaching 187-244 days of age to determine, by the presence of pigmented sites of implantation, whether they had become pregnant and aborted or resorbed fetuses (Davis \& Emlen, 1948). The testes of randomly selected males were removed to identify gross testicular abnormalities and to measure the testes-to-body weight ratio.

Analyses of variance with Scheffe's test for contrasts were performed on measures of sexual maturation where appropriate (Sokal \& Rohlf, 1969). oaded from Bioscientifica.com at 04/26/2023 08:36:30AM 


\section{Results}

\section{Males}

All males of the three stocks had scrotal testes by 27 days of age with little variation between stocks. Because of the subjective nature of this measurement and the similarity of the three stocks a statistical comparison was not made.

Ages at first appearance of mature spermatozoa in the testes did not differ among stocks (Table $1 ; \mathrm{F}=1.4$, d.f. $=2 / 69, P>0.25$ ) but body weights were significantly different (Table 1 ; $\mathrm{F}=70 \cdot 6$, d.f. $=2 / 69, P<0.001)$ : wild rats were significantly lighter than Long-Evans males $(P$ $<0.001)$ which were lighter than Sprague-Dawley males $(P<0.005)$.

Table 1. Measures of sexual maturation in male wild, Long-Evans and Sprague-Dawley stocks of Norway rats

\begin{tabular}{lllll}
\hline Variable & \multicolumn{1}{c}{ Stock } & $\begin{array}{c}\text { No. } \\
\text { of rats }\end{array}$ & Age (days) & Body weight (g) \\
\hline Mature spermatozoa & Wild & 24 & $42.1 \pm 1.9$ & $111.5 \pm 17.3$ \\
first obtained & Long-Evans & $21^{*}$ & $42.7 \pm 2.8$ & $156.4 \pm 14.9$ \\
& Sprague-Dawley & 27 & $41.7 \pm 1.7$ & $178.0 \pm 26.4$ \\
First copulation & Wild & $23 \dagger$ & $64.6 \pm 20.5$ & $185.5 \pm 62.8$ \\
& Long-Evans & $19 \ddagger$ & $58.7 \pm 3.2$ & $258.4 \pm 27.4$ \\
& Sprague-Dawley & $24 \ddagger$ & $53.9 \pm 5.5$ & $275.3 \pm 42.6$ \\
\hline
\end{tabular}

Values are mean \pm s.d.

* Two of the original animals died.

$\dagger$ One rat did not copulate within 239 days.

$\ddagger$ Data lost for 2 Long-Evans and 3 Sprague-Dawley males.

Analyses of variance for the effect of rat stocks on age and body weight at first copulation were significant (Table $1 ; \mathrm{F}=4 \cdot 1$, d.f. $=2 / 63, P<0.025$ and $\mathrm{F}=23 \cdot 2$, d.f $=2 / 63, P<0.001$, respectively). Wild males were significantly older and lighter than Sprague-Dawley males when they first engaged in copulatory behavior $(P<0.025$ and $P<0.001$, respectively). Long-Evans males were intermediate. Ages of wild and Sprague-Dawley males did not differ significantly from that of Long-Evans rats at first copulation. Long-Evans rats were significantly heavier than wild males $(P<0.001)$ but similar in weight to Sprague-Dawley males.

All but one wild male copulated and sired offspring; all domestic males were fecund.

\section{Females}

Ages at vaginal opening were significantly different between stocks (Table $2 ; \mathrm{F}=14.4$, d.f. $=2 / 74, P<0.001$ ). Wild females were on average 5 days older at vaginal opening than the two stocks of domestic females $(P<0.001$ in each comparison); Long-Evans and Sprague-Dawley females did not differ. Body weights at vaginal opening were also significantly different (Table 2; $\mathrm{F}=80 \cdot 1$, d.f. $=2 / 73, P<0.001$ ): wild females were significantly lighter than Long-Evans female rats $(P<0.001)$ which were lighter than the Sprague-Dawley females $(P<0.001)$.

First oestrus closely followed the time of vaginal opening, and ages and body weights at first oestrus followed the same pattern as that of vaginal openings (Table $2 ; \mathrm{F}=24.2$, d.f. $=2 / 74, P$ $<0.001$, and $\mathrm{F}=53.1$, d.f. $=2 / 73, P<0.001$, respectively) including the paired comparisons between stocks.

Stocks did not differ in length of the first oestrous cycle (Table $2 ; F=0.2$, d.f. $=2 / 29$ ).

Parturitions and post-mortem examinations for pigmented sites of implantation revealed that $24 / 25(96 \%)$ wild females conceived and $21(88 \%)$ of those that conceived gave birth. All of the domestic females conceived and gave birth. 
Table 2. Measures of sexual maturation and fecundity in female wild, Long-Evans and Sprague-Dawley stocks of Norway rats

\begin{tabular}{|c|c|c|c|c|}
\hline Variable & Stock & $\begin{array}{l}\text { No. } \\
\text { of rats }\end{array}$ & Age (days) & Body weight (g) \\
\hline Vaginal opening & $\begin{array}{l}\text { Wild } \\
\text { Long-Evans } \\
\text { Sprague-Dawley }\end{array}$ & $\begin{array}{l}26 \\
25 \\
26\end{array}$ & $\begin{array}{l}42.5 \pm 5.7 \\
37.1 \pm 2.9 \\
37.5 \pm 2.7\end{array}$ & $\begin{aligned} & 81.1 \pm 9.2 \\
& * 105.9 \pm 13.0 \\
& 126.0 \pm 15.5\end{aligned}$ \\
\hline First oestrus & $\begin{array}{l}\text { Wild } \\
\text { Long-Evans } \\
\text { Sprague-Dawley }\end{array}$ & $\begin{array}{l}26 \\
25 \\
26\end{array}$ & $\begin{array}{l}45.7 \pm 6.9 \\
37.9 \pm 3.3 \\
37.8 \pm 2.8\end{array}$ & $\begin{array}{r}86.6 \pm 9.6 \\
* 110.7 \pm 16.5 \\
127.7 \pm 16.2\end{array}$ \\
\hline First conception & $\begin{array}{l}\text { Wild } \\
\text { Long-Evans } \\
\text { Sprague-Dawley }\end{array}$ & $\begin{array}{l}21 \dagger \\
25 \\
25 \ddagger\end{array}$ & $\begin{array}{l}55 \cdot 7 \pm 22 \cdot 6 \\
41 \cdot 3 \pm 2.9 \\
42 \cdot 0 \pm 4 \cdot 5\end{array}$ & $\begin{array}{r}103.2 \pm 23.3 \\
* 125.9 \pm 17.6 \\
* 151.8 \pm 29.3\end{array}$ \\
\hline $\begin{array}{l}\text { Length of first } \\
\text { oestrous cycle (days) }\end{array}$ & $\begin{array}{l}\text { Wild } \\
\text { Long-Evans } \\
\text { Sprague-Dawley }\end{array}$ & $\begin{array}{r}11 \\
9 \\
12\end{array}$ & $\begin{array}{l}4.5 \pm 1.0 \\
4.7 \pm 0.9 \\
4.3 \pm 1.7\end{array}$ & \\
\hline $\begin{array}{l}\text { Litter size at } \\
\text { first parturition }\end{array}$ & $\begin{array}{l}\text { Wild } \\
\text { Long-Evans } \\
\text { Sprague-Dawley }\end{array}$ & $\begin{array}{l}20 \\
25 \\
24\end{array}$ & $\begin{array}{r}6.4 \pm 1.0 \\
9.7 \pm 1.8 \\
10.4 \pm 2.8\end{array}$ & \\
\hline
\end{tabular}

Values are mean \pm s.d.

* Body weight not recorded for one individual in sample.

$\uparrow$ One wild female escaped from its cage and 4 did not give birth.

$\ddagger$ One female not considered because of a wound received from cagemate.

Ages and weights at first conception were significantly different between stocks (Table 2; F $=8.7$, d.f. $=2 / 67, P<0.001$, and $\mathrm{F}=22.7$, d.f. $=2 / 65, P<0.001$, respectively). Wild females conceived significantly later than did females of the 2 domestic stocks $(P<0.05$ in each comparison) whereas the domestic stocks did not differ. Body weight at first conception was significantly lower for wild rats than for Long-Evans females $(P<0.05)$ and the latter were significantly lighter than Sprague-Dawley rats $(P<0.05)$.

Litter size at first parturition differed significantly (Table $2 ; \mathrm{F}=22.9$, d.f. $=2 / 66, P<$ $0.001)$ : wild females produced significantly smaller litters than did either domestic stock $(P<$ 0.001 in each comparison) whereas the domestic stocks did not differ.

Only $9 / 21(43 \%)$ wild females that gave birth reared all or part of their offspring to weaning. (One litter was cannibalized at birth and 11 litters were abandoned at various stages before weaning.) All domestic females raised a portion, if not all, of their offspring to weaning age. This difference was significant $\left(\chi^{2}=29.5\right.$, d.f. $\left.=1, P<0.001\right)$.

\section{Discussion}

The results of this study support the hypothesis that domestic Norway rats attain sexual maturity and reproductive success at an earlier age than their wild counterparts. Although it seems reasonable to postulate that artificial selection (both intentional and unintentional) was largely responsible for these changes during domestication, the role of "natural selection in captivity" (selection other than that instituted by man) cannot be discounted (Price \& King, 1968). In either case the data do not reveal whether the differences observed are due to stock differences in genotype or a genotype-environmental interaction (i.e. the environmental conditions to which the animals were exposed could be optimal for domestic stocks and suboptimal for wild rats). In addition, the wild rats used in the present study may or may not be representative of the wild ancestors of the domestic stocks studied. Therefore, inferences regarding the effects of domestication on the rate of sexual maturation in this species must be made with caution. 
In the present study, domestic females (both stocks) became fertile about 14 days earlier than did the wild females. At this stage of development domestic rats weighed significantly more than did wild females, suggesting that the acceleration of sexual maturation in domestic females may be linked to an increased rate of growth. However, the fact that Sprague-Dawley females were significantly heavier than Long-Evans females upon reaching puberty even though developmental ages were the same would indicate that rates of physical growth and age at sexual maturity are not always correlated when making comparisons between stocks or strains of a species. Hence, differences between stocks in rate of growth do not provide a satisfactory explanation for the relatively longer period of sexual maturation of the wild rats.

Field data (Leslie, Perry \& Watson, 1945; Perry, 1945; Davis, 1949) indicate that free-living wild rats do not reach sexual maturity sooner than the captive-reared wild rats used in the present study, suggesting that rearing in a laboratory environment did not delay puberty in these animals.

Copulatory behavior was first evident in wild rats about 7-10 days later than in domestic males. In nature, selection for early puberty in rats may be limited because of the inability of very young males to compete successfully with older, more experienced males for oestrous females (Steiniger, 1950). In captivity, one male is usually paired with one or more females of similar age (often at weaning), thus eliminating male-male competition for females. Under these conditions, the early maturation of copulatory function would confer an important selective advantage to the domestic male.

Disparity in litter sizes of wild and domestic rats in the present study corresponded closely to that reported previously (King \& Donaldson, 1929; Barnett, 1958; Sloan, 1973) in captive-reared wild and domestic Norway rats. In all of these studies the percentage of wild rat pairs that produced offspring was relatively low and litter sizes for wild females were about two-thirds that of domestic rats. In other reports (Miller, 1911; Davis, 1951; Boice, 1972) litter sizes of free-living and captive wild-caught wild rats were comparable with those of domestic females. This suggests that the reduced litter sizes of wild females during the first few generations in captivity are in some way related to rearing in a laboratory environment and domestication would serve to remove these environmental constraints. King (1939) reported that the litter size of captive wild rats reached a level comparable with that of domestic and free-living wild rats after about 20 generations of breeding in captivity.

The rats used in the present study were handled periodically from the time of weaning. Although a proper control for handling was not instituted, data from this and another study in the same laboratory (Price, 1980) imply that handling improves the fecundity of wild rats reared in captivity. Of 61 non-handled wild males that were born and reared in the laboratory only 27 (44\%) copulated with hormone-induced oestrous females (domestic). In contrast, 22/23 (96\%) wild-caught males attained successful copulations, a proportion almost identical to that obtained by the males in the present study $(23 / 24)$. If handling affects the mating success of wild rats in captivity it would appear to minimize (rather than contribute to) differences between wild and domestic stocks in this environment.

We thank W. Borgstede and A. Clark for assistance in various stages of this investigation. This paper was based on a thesis submitted by B.R.C. in partial fulfilment of the M.S. degree at the State University of New York College of Environmental Science and Forestry, Syracuse.

\section{References}

Asdell, S.A. (1964) Patterns of Mammalian Reproduction, 2nd edn. Cornell University Press, Ithaca.

Barnett, S.A. (1958) Laboratory methods for behavior study of wild rats. J. Anim. Tech. Assoc. 9, 6-14.
Boice, R. (1972) Some behavioral tests of domestication in Norway rats. Behaviour 42, 198-231.

Brown, R.E. (1974) Sexual arousal, the Coolidge effect and dominance in the rat (Rattus norvegicus). Anim. Behav. 22, 634-637. 
Davls, D.E. (1949) The weight of wild brown rats at sexual maturity. J. Mammal. 30, 125-130.

Davis, D.E. (1951) The relation between level of population and pregnancy of Norway rats. Ecology 32, 459-461.

Davis, D.E. \& Emlen, J.J. (1948) The placental scar as a measure of fertility in rats. J. Wildl. Mgmt 12 , 162-166.

King, H.D. (1939) Life processes in grey Norway rats during fourteen years in captivity. Am. Anat. Memoirs 17, 1-72.

King, H.D. a Donaldson, H.H. (1929) Life processes and size of the body and organs of the grey Norway rat during ten generations in captivity. Am. Anat. Memoirs 14, 1-106.

Lealie, P.H., Perry, J.S. \& Watson, J.S. (1945) The determination of the median body weight at which female rats reach maturity. Proc. zool. Soc. Lond. $115,473-488$.

Martin, K.H. A Richmond, M.E. (1972) A method for repeated sampling of testis tissue from small mammals. Lab. Anim. Sci. 22, 541-545.
MHler, N. (1911) Reproduction in the brown rat (Mus norvegicus). Am. Nat. 45, 623-635.

Perry, J.S. (1945) The reproduction of the wild brown rat (Rattus norvegicus). Proc. zool. Soc. Lond. 115, $19-46$.

Price, E.O. (1980) Sexual behaviour and reproductive competition in male wild and domestic Norway rats. Anim. Behav. 28, 657-667.

Price, E.O. King, J.A. (1968) Domestication and adaptation. In Adaptation of Domestic Animals, pp. 34-35. Ed. E. S. E. Hafez. Lea and Febiger, Philadelphis.

Sadleir, R.M.F.S. (1969) The Ecology of Reproduction in Wild and Domestic Mammals. Methuen, London.

Sloan, RJ. (1973) Relationships Between Behavior and Reproduction in Captive Wild Norway Rats, Rattus norvegicus. $\mathrm{Ph}$. D. thesis, State University of New York, Syracuse.

Solsal, R.R. \& Rohlf, F.J. (1969) Biometry. W.H. Freeman, San Francisco.

Steiniger, R. (1950) Beiträge zur Soziologie und sonstigen Biologie der Wanderratte. Z. Tierpsychol. 7, 356-379.

Received 16 January 1981 